\title{
Application of Sulphoaluminate Cement to Repair Deteriorated Concrete Members in Chloride Ion Rich Environment-A Basic Experimental Investigation of Durability Properties
}

\author{
Gaochuang Cai* and Jun Zhao** \\ Received February 11, 2015/Accepted December 11, 2015/Published Online February 26, 2016
}

\begin{abstract}
This paper presents a basic experimental investigation of the durability properties of Sulphoaluminate cement concrete (SACC) and Portland Cement Concrete (PCC). It is to discuss the potential application of Sulphoaluminate cement towards the repair of deteriorated concrete members in chloride ion-rich environment such as coastal engineering, using a SACC repair layer with higher strength than original damaged concrete. The chloride-related durability properties of SACCs were comprehensively studied through some experiments including concrete internal chloride ion content test, chloride ion migration test, $X$-ray diffraction analysis, scanning electron microscopy and pore structure analysis, when compared with the results of PCCs that have same mix proportion and curing conditions. The analyses and comparisons presented in this paper verified the SACC repair layer has high early strength and chloride-related durability which will effectively improve the capacity of damaged concrete to resist chloride ion penetration. When without any admixtures, compared with PCCs' results, SACCs can provide more compactness hardened internal structures, more micro fillers between internal cracks and more favorable hydration products to bond/resist chloride ions, as well as can also provide lower porosity and more winding pore passageway to resist and postpone the transportation of chloride ion in the concretes. Based on the investigation, the chemical and physical mechanisms of SACC were discussed.
\end{abstract}

Keywords: sulphoaluminate cement, durability, chloride ion penetration, XRD, SEM, pore structure

\section{Introduction}

In order to develop a more convenience life and work environment, massive infrastructures and buildings are being constructed all over the world, especially in developing countries. As one of used-frequently construction materials and second most consumed resource, concrete has been used widely and is being consumed recently over 2 billion metric ton every year (Crow, 2008). Many issues involving to concrete structures are becoming the key factors to many industries affecting total societal development in the future such as carbon dioxide emission from PC production, premature strength and property deteriorations caused by aggressive environmental impacts, etc. Researchers can't deny the fact that the above problems are going to get worse as described in previous studies: by 2050 , concrete is predicted to reach four times of the level in 1990 (Crow, 2008).

Strength and durability are two important indexes to assess the quality and properties of concretes. As a consequence, FIB (1999) suggested a generally accepted aim is "to achieve an acceptable probability that the structure being designed will perform satisfactorily during its intended life", when concrete structures are designed. The life time of concrete structures mainly depends on the ability of concrete to resist chemical attack, abrasion or various environmental impacts etc. These deteriorations focus on the losing of various strengths of concrete, corrosion of reinforcements, concrete cracking, expansion and spalling of concrete cover and other potential danger effects. Hence, a completed design of concrete structure should consider carefully the associated actions from mechanical loads and environmental impacts, both.

For these reasons, the durability of concrete structures has being concerned and became one important and ineluctable research topic in civil engineering industries. The main objectives of these durability studies, summarily, can be concluded as: to analyze action mechanics to guide concrete design and to comparatively study the management and repair methods of existing concrete structures. Among of these, due to chloride ion penetration is one of main reasons that lead to the corrosion of reinforcements in concrete, in the past 30 years, the characteristics of the transportation, absorbing/bonding, diffusion and critical corrosion level of chloride ion in various concretes had been studied adequately by many researchers (e.g., Gowripalan, 1998; Montemor et al., 2003; Angst et al., 2009; Shi et al. 2012). Fig. 1

\footnotetext{
*Researcher, CERG, Faculty of Engineering Technology, Hasselt University, Diepenbeek, Belgium (E-mail: gaochuang.cai@uhasselt.be)

**Professor, School of Mechanics and Engineering Science, Zhengzhou University, Zhengzhou, China (Corresponding Author, E-mail: zhaoj@zzu.edu.cn)
} 


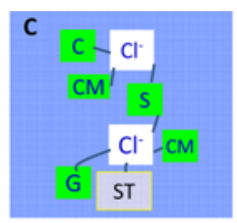

(a)


(c)

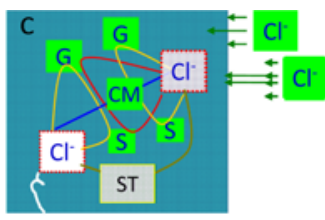

(b)
Wet concrete (electrolyte solution) Anode: $\mathrm{Fe}+2 \mathrm{Cl} \rightarrow\left(\mathrm{Fe}^{2+}+2 \mathrm{Cl}\right)+2 \mathrm{e}$ Cathode: $\mathrm{O}_{2}+2 \mathrm{H}_{2} \mathrm{O}+4 \mathrm{e}^{-} \rightarrow 4 \mathrm{OH}$

Necessary conditions : water, air and chloride

Fig. 1. Possible Actions/effects of Chloride Ions and Steel Electro
Chemical Corrosion in Concrete: (a) Internal Mixed Chloride, (b) External Diffused Chloride, (c) Electrochemical Corrosion of Steel in Concrete

(a) and (b) show the possible reactions/effects between internal/ external chloride ions and cement paste/concrete structures respectively. The two major ways of chloride ions affecting concrete are internal mixed and external diffusion or penetration. The former mainly involves the interior composition of applied cement, aggregates, admixtures and water when concrete was made. On the other hand, sea water, fog, sea salt, aggressive underground/soil water, deicing-salt and firefighting water can take external chloride ion into concrete/reinforced concrete (RC) which leads further corrosion via diffusing or penetrating way. When water and air both exist in the internal structure of concrete, as shown in Fig. 1(c), as a high active ion, chloride ion can generally destroy the alkaline protective film at the surface of steel bars which impacts significantly internal stableness and subsequently triggers the electrochemical corrosion of steel bar in concrete resulting in rapid development of internal expansion cracks.

In order to improve the durability properties related to chloride ion penetration in various concrete members, considerable improvement methods have been proposed, such as using recycled aggregate concrete (Ryu, 2002; Ann et al., 2008; Vázquez et al., 2014); reducing water/binder ratio (e.g., Andrade, 1993; Ryu, 2002; Oh et al., 2002); using some supplementary cementitious materials such as blast furnace slag (Oh et al., 2002; Hooton, 2002), spent cracking catalyst (Zornoza et al., 2009), fly ash (Dhir, 1999; Oh et al., 2009), silica fume (Alexander et al., 1999; Oh et al., 2009), Korean Metakaolin binders (Kim et al., 2007), ground granulate blast-furnace slag (Yeau et al., 2005), volcanic ash (Hossain and Lachemi, 2004) nano-particles (He and Shi, 2008; Zhang and Li, 2011) and silica rice husk (Otsuki et al., 2003; Cordeiro et al., 2009; Abu et al., 2010); adjusting the fineness of fly ash (Chindaprasirt et al., 2007) and maximum size of aggregate (Mehta and Monteiro, 2006); However, these endeavors also could bring some negative impacts. For example, added admixtures could produce potential unsafety or different internal stress, and lower water/cement ratio maybe will make concrete more easily generate initial shrinkage cracks etc. Some more stable and safety improvement methods have been concerned in research community, as using no admixture modified cement system.

As a low heat-low carbon-rapid hardening cement, Sulphoaluminate cement (SAC) has been used increasingly in building and infrastructural structures at cold region in China and specific engineering structures due to its extraordinary required properties such as high early ages strength and freezing resistance, low permeability and alkalinity and so on (Yan, 1993; Kasselouri et al., 1995; Wang et al., 1999; Andac and Glasser, 1999; Xin et al., 2000, 2005; Bernardo et al., 2006; Zhou et al., 2006; Qian et al., 2008; Chang et al., 2009; Quilin, 2011; Zhao et al., 2011a, $2011 b$, 2014). Besides, due to the main row burning materials of $\mathrm{SAC}$ is low grade Bauxite, the carbon dioxide emission from SAC production is lower than PC ones. Based on these results reported in the studies, SACC can be proposed as an effective material to repair fast and easily deteriorated concrete members in chloride ion environment. Fig. 2 illustrates roughly the basic information of this repair proposal as two examples with different deterioration degrees. After chipping surficial deteriorated concrete layer and cleaning the new face, some bond rivets are firstly embedded into old concrete to ensure more sufficient connection between new repair layer and old concrete. Subsequently, a new SACC repair layer is constructed with higher strength than original concrete and using finer coarse aggregates. If the corrosion depth of concrete is large, some reinforcements can be set in the repair layer, as shown in Fig. 2. Based on previous research, Meng et al. (2010) confirmed that the bonding strength between old concrete/mortar and new SAC concrete/mortar can satisfy completely the basic requirements for RC structures. Regarding the durability of SACC in chloride ion rich environment, however, just a few experimental studies can be obtained, especially the one without any admixture which indicating this system can avoid producing potential unsafety (Rongbing and Jian, 2005) or other disadvantageous like as internal stress change described previously (Nmai et al., 1994).

The primary objectives of the paper are to experimentally study chloride-related durability properties of SACC, and to elementarily verify the above repair proposal, including 1) investigate



Fig. 2. Proposal to Repair Deteriorated Concrete in Chloride Environment 
SACCs' capacities of bonding chloride ions and resisting to chloride ions diffusion; 2) present the effects of chloride ion diffusion on chemical change in SACC; 3) compare the difference between the physical characteristics of SACC and PCC; 4) analyze the characteristics of internal pore structure in SACC and 5) explain mechanism of bonding and resisting chloride ion of SACC.

\section{Utilization of SAC in China-a Short Review}

As descried in mass previous studies, SAC has been used increasingly in various practical engineering in Chinese cold region since 1975 when it was developed by Chinese researchers. In this section, the main utilizations of SAC can be summarized, as follows,

Rapid repairing engineering - the high-early-strength series SACs not only have excellent strength at early stage, but also can present a good strength development at later stage as well (Xin et al., 2005; Bernardo et al., 2006; Qian et al., 2008; Zhao et al., 2011a, 2014). Besides, the micro-expansion property of SACC also makes this cement can find its application space in rapidrepair engineering, since it can fill effectively and rapidly internal micro-cracks of damaged concrete (Lu et al., 1996).

Construction in winter-SACC shows an excellent property to resist freezing-thawing cycle action to concrete structures, which is usually-concerned in winter constructions and the concrete structure located at cold region. For instance, it was reported that this cement can be directly applied in RC structures just using little anti-freezing admixture even when the temperature of construction environment ranged from $-20^{\circ} \mathrm{C}$ to $0^{\circ} \mathrm{C}$ (Wang et al. 1999; Zhang and Wang 1993).

Special Engineering - due to its high level corrosion resistance, wear resistance (Glasser and Zhang 2001; Ye et al., 2007) and penetrability resistance capacity (Li et al., 2008), SACC can be used in the concrete structures required to meet some special requirements such as airport road engineering and the others subjected to hazardous and harmful environments.

Precast engineering - when the constructed structures located at field or some large-span concrete elements like bridges, in order to convenient construction, precast concretes present their many advantages, includes reduction of shrinkage and creep, control of service deflections and significant reduction of construction time (CE 241, 2004; Geren et al., 1994). In order to obtain high early strength for concrete, mass methods to improve the curing of precast concrete had been developed such as steam curing (Shideler and Chamberlin, 1949; Higginson, 1961). However, this curing generally results in the increase of product cost and energy consumption. From this viewpoint, SACC's high rate of strength development and low dry shrinkage at early stage can make SAC can be used widely in precast concrete.

Glass fiber reinforced concrete (GFRC) - the previous researchers (Quilin, 2001; Zhou et al., 2006) reported SAC can provide lowalkaline solution environment in concrete, e.g., $\mathrm{PH}$ value of internal pore solution in concrete can be controlled under 12
(Zhou et al., 2006). It indicated that this cement may be a good option for the bind materials for GFRC, especially low alkaline series SACs that can control concrete with a $\mathrm{PH}$ value under 10.5 , reported in the same study. Although it was well known that the low-alkaline solution can't provide an effective and stronger passive film for steel bars at initial stage, just only tiny corrosion to steel bars may happen when adequate air and water can be obtained in the internal pore solution. Besides, along with stable hydration of SAC, concrete will become more compactness as well as water and air in concrete start to decrease or disappear almost completely. These make that the corrosion of steel bar can be controlled under a tiny level in SACC which will increase the bond between concrete and reinforcements.

\section{Experimental Investigations}

As described previously, to examine the above repairing proposal to concrete structures in chloride ion environment, firstly this study experimentally investigates the chloride-related durability properties of PC and SAC concretes. On the basis of the results, the authors try to explain chloride ion bonding and resisting mechanisms of SACC from physical and chemical views, both.

\subsection{Materials Properties and Specimens' Preparation}

Cement-Sulphoaluminate cement applied in the study is rapid-hardening type cement, which can make concretes to obtain some excellent early properties such as high strength, low permeability and alkalinity. The cement mainly consisted of two mineral compositions, i.e., anhydrous $\mathrm{C}_{4} \mathrm{~A}_{3} \mathrm{~S}$ and $\mathrm{C}_{2} \mathrm{~S}$, as well as has a specific superficial area of greater than $350 \mathrm{~m}^{2} / \mathrm{kg}$ and an initial setting time of more than $25 \mathrm{~min}$. Table 1 lists the chemical characteristics of SAC and Portland Cement (PC). As shown in this table, the main chemical compositions of SAC are $\mathrm{SiO}_{2}$, $\mathrm{Al}_{2} \mathrm{O}_{3}$ and $\mathrm{CaO}$, while the ones of $\mathrm{PC}$ are $\mathrm{SiO}_{2}$ and $\mathrm{CaO}$.

Mortar and concrete-in order to evaluate the chloride ionbonding capacities of two cement systems, some mortar specimens were made using distilled water and artificial sand as fine aggregate for removing the negative effects caused by their potential impurity. The mix proportion of mortar specimens is listed in Table 2. On the other hand, to assess the chloride ion

Table 1. Chemical composition of $\mathrm{PC}$ and SAC (\%)

\begin{tabular}{c|c|c|c|c|c|c|c|c}
\hline Cements & $\mathrm{SiO}_{2}$ & $\mathrm{Al}_{2} \mathrm{O}_{3}$ & $\mathrm{Fe}_{2} \mathrm{O}_{3}$ & $\mathrm{CaO}$ & $\mathrm{MgO}$ & $\mathrm{TiO}_{2}$ & $\mathrm{SO}_{3}$ & Others \\
\hline PC & 22.8 & 9.37 & 3.4 & 55.2 & 2.99 & 1.1 & 4.3 & 0.84 \\
\hline SAC & 12.46 & 29.72 & 2.55 & 42.44 & 0.64 & 1.82 & 9.52 & 0.75 \\
\hline
\end{tabular}

Table 2. Mix Proportion of Mortar

\begin{tabular}{c|c|c|c|c|c|c}
\hline NO. & W/C & age/d & $\begin{array}{c}\text { Water } \\
\left(\mathrm{kg} / \mathrm{m}^{3}\right)\end{array}$ & $\begin{array}{c}\mathrm{Cement} \\
\left(\mathrm{kg} / \mathrm{m}^{3}\right)\end{array}$ & $\begin{array}{c}\text { Sand } \\
\left(\mathrm{kg} / \mathrm{m}^{3}\right)\end{array}$ & $\begin{array}{c}\mathrm{NaCl} \\
\left(\mathrm{kg} / \mathrm{m}^{3}\right)\end{array}$ \\
\hline $\mathrm{MI}_{1}$ & 0.5 & 28 & 200 & 400 & 600 & 2 \\
\hline $\mathrm{MI}_{2}$ & 0.5 & 28 & 200 & 400 & 600 & 4 \\
\hline $\mathrm{MI}_{3}$ & 0.5 & 28 & 200 & 400 & 600 & 7 \\
\hline $\mathrm{MI}_{4}$ & 0.5 & 28 & 200 & 400 & 600 & 10 \\
\hline $\mathrm{MI}_{5}$ & 0.5 & 28 & 200 & 400 & 600 & 20 \\
\hline
\end{tabular}


Table 3. Details of Concrete Mix Proportion

\begin{tabular}{c|c|c|c|c|c|c|c}
\hline No. & w/c & $\begin{array}{c}\text { Water } \\
\left(\mathrm{kg} / \mathrm{m}^{3}\right)\end{array}$ & \multicolumn{2}{|c|}{$\begin{array}{c}\text { Aggregates } \\
\left(\mathrm{kg} / \mathrm{m}^{3}\right)\end{array}$} & $\begin{array}{c}\text { Cement } \\
\left(\mathrm{kg} / \mathrm{m}^{3}\right)\end{array}$ & $\begin{array}{c}\text { Slump } \\
\mathrm{mm}\end{array}$ & $\begin{array}{c}\text { Curing } \\
\text { time } \\
(\text { days })\end{array}$ \\
\hline $\mathrm{C} 30$ & 0.57 & 210 & 886 & 886 & 368 & 89 & $3 / 7 / 28 / 56$ \\
\hline $\mathrm{C} 40$ & 0.47 & 210 & 796 & 897 & 447 & 76 & $3 / 7 / 28 / 56$ \\
\hline $\mathrm{C} 45$ & 0.44 & 210 & 748 & 915 & 477 & 65 & $3 / 7 / 28 / 56$ \\
\hline $\mathrm{C} 50$ & 0.38 & 200 & 731 & 893 & 526 & 57 & $3 / 7 / 28 / 56$ \\
\hline
\end{tabular}

penetration depths in two kind concretes, some PCC and SACC specimens were constructed using same mix proportion shown in Table 3. Natural crushed granite stone with maximum diameter of $10 \mathrm{~mm}$ and river sands with fineness modulus of 2.6 were applied as coarse and fine aggregate, respectively. All tested specimens were cured in a standard moist chamber with a relative humidity of $90-95 \%$ and a temperature ranged from $18^{\circ} \mathrm{C}$ to $22^{\circ} \mathrm{C}$.

\subsection{Test Methods}

\subsubsection{Chloride Ion Content Test}

Based on Chinese test code SL352-2006 for hydraulic concrete (Chinese test standard, 2006), described in Sections 4.34 and 4.35 , using a chemical titration method similar to NT BUILD 208 (NordTest, 1999), the free and total chlorine ion contents in mortar were measured. Subsequently, the chemical bonded chloride ion content in mortar specimen can be computed. Main experimental procedures include: grinding and selection of test sample, drying and cooling treatment, water immersion (24h), as well as chemical titration measurement.

For the total chloride ion content, firstly, a mixed solution using test mortar powder and containing chloride ions was made. In order to estimate roughly chloride ion content in the above solution, moderate silver nitrate was added to precipitate the mixed solution to form new mixed solution. Subsequently the excess of silver ions in the new solution are titrated using a standard potassium thiocyanate (KSCN). Titration volume will be determined when a red solution presents steadily 5-10 seconds during a drastic shocking. On the other hand, for the free chloride ion content in mortar solution, some standard phenolphthalein reagents were added firstly to make the tested solution presenting reddish color, and then using dilute sulphuric acid neutralize until to be white solution. Subsequently, some indicator solutions (Potassium chromate $\mathrm{K}_{2} \mathrm{CrO}_{4}$ ) were instilled to look for an exact volume of silver nitrate which can reacted with the solution into a brick-red complex solution.

\subsubsection{Chloride Migration Test (non-steady-state chloride migration test, NT BUILD 492)}

Three circular prismatic concrete specimens (diameter $f=100$ $\pm 2 \mathrm{~mm}$, height $H=50 \pm 5 \mathrm{~mm}$ ) and three cubic specimens (size: $100 \times 100 \times 100 \mathrm{~mm}$ ) were made for each mix proportion, to measure chloride ion diffusion in the concretes and evaluate their compressive strength, respectively. In the paper, the chloride ion diffusion coefficient $(C D C)$ is measured through a Non-steady-state chloride migration test (NSSCM) according to the European standard method-NT Build 492 (NordTest, 1999). The test specimens were dried and placed on the bottom of a rubber sleeve with diameter of $110 \mathrm{~mm}$, as shown in Fig. 4. An external electric current is imposed through the tested concrete specimen paralleling with vertical axis to simulate chloride ions diffusion from concrete surface to its internal structure. After a specified test time in NT Build 492, concrete specimen is removed from rubber sleeve and cut into two same halves. Some silver nitrate $\left(\mathrm{AgNO}_{3}\right)$ solutions with certain concentration were sprayed on the cutting section of the halves. Subsequently, the depth of chloride ion penetration $X_{d}$ is presented and measured according to a presented visible white precipitation. According to code NT Build 492, the calculation of $C D C$ can be given by,

$$
D_{n s s m}=\frac{0.0239(273+T)}{(U-2) t} \times\left[X_{d}-0.0238 \sqrt{\frac{H(273+T)}{(U-2)}}\right]
$$

In this equation, $D_{n s s m}$ represents $C D C$ of concrete, in $m^{2} s^{-1} ; U$ is an absolute value of applied voltage, in volt ( $v) ; T$ is an average value of initial and final environment temperature of the anode solution, in Kelvin $(K) ; H$ is the thickness of specimen, in meter $(m) ; X_{d}$ is the average depth of chloride ion penetration measured from two halves, in meter $(m)$; $t$ is test duration, in second $(s)$.

\subsubsection{Scanning Electron Microscope (SEM) and Pore Structural Analysis}

By scanning sample with a focused beam of electrons, Scanning Electron Microscope (SEM) can produce images of a sample, which is a kind of electron microscope. In this paper, some cylinder paste/concrete specimens with diameter of $8 \mathrm{~mm}$ and height of $5 \mathrm{~mm}$ were prepared for SEM test to compare the difference of microstructure between PC and SAC mortar/ concretes. In addition, through a mercury porosimetry test: ISO 15901-1:2005 (British standard 2007), the total porosity and pore size distribution of PCC and SACC were studied, which using three cubic concrete specimens (size: $10 \mathrm{~mm} \times 10 \mathrm{~mm} \times 10 \mathrm{~mm}$ ) took out from corresponding cubic specimens $(100 \mathrm{~mm} \times 100$ $\mathrm{mm} \times 100 \mathrm{~mm}$ ) at curing time of 7 and 28 days, respectively.

\section{Experimental Results and Observations}

\subsection{Compressive Strength Development}

Considering the fact that the strength affects many properties of concrete, the research is necessary regarding compressive strength development of SACC for their durability investigation. Due to the compressive strengths of two kinds of concrete have been studied sufficiently in previous researches, this paper just presents simply this property. two important findings have been confirmed in the two concretes, will help to understand well the following durability analyses. As shown in Fig. 3, similar to the research results reported by Zhao et al. (2014), these two concretes with same $\mathrm{w} / \mathrm{c}$ ratio present almost same long-term 

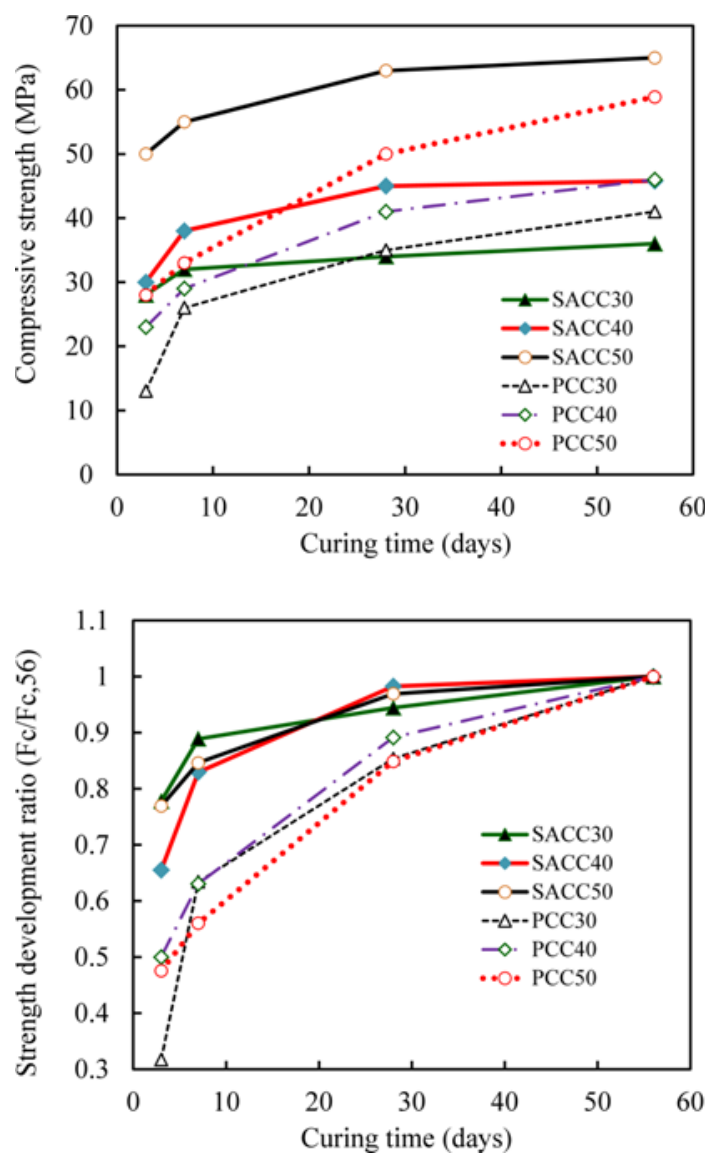

Fig. 3. Concrete Compressive Strength and Its Development Ratio

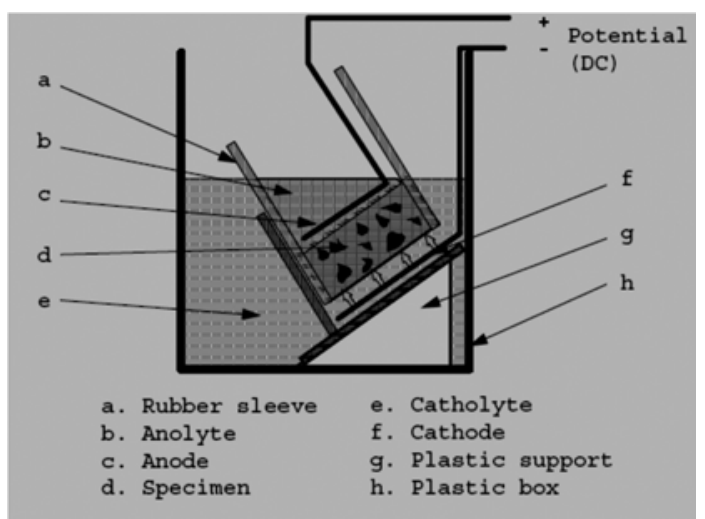

Fig. 4. Set-up for Non-steady-state Chloride Migration Test in NT BUILD 492 (NordTest, 1999)

compressive strength such as the plotted ones at 56 days. Besides, the results in this figure confirmed that the development ratio of the compressive strength of SACC is faster than PCC at early stages, for example, the strength at $3^{\text {rd }}$ day can reach $0.65 \sim 0.75$ times of the one at $56^{\text {th }}$ day. This property is very helpful for the repair of concrete structures and to enhance the resisting capacity of concrete to chloride ion penetration at early stages of repair, which absolutely will affect the durability of concretes at later stages of their lifetime.
Table 4. Results of Chloride lon Content Test in Two Cement-based Mortars

\begin{tabular}{c|c|c|c|c|c|c}
\hline Test No. & $\mathrm{W} / \mathrm{C}$ & $\begin{array}{c}\text { Cement } \\
\left(\mathrm{kg} / \mathrm{m}^{3}\right)\end{array}$ & $\begin{array}{c}\mathrm{NaCl} \\
\left(\mathrm{kg} / \mathrm{m}^{3}\right)\end{array}$ & $\mathrm{Pw} / \%$ & $\mathrm{Pt} / \%$ & $\mathrm{P}_{\mathrm{b}} / \%$ \\
\hline PMI1 & 0.5 & 400 & 2 & 0.154 & 0.480 & 0.326 \\
\hline PMI2 & 0.5 & 400 & 4 & 0.650 & 1.070 & 0.420 \\
\hline PMI3 & 0.5 & 400 & 7 & 0.967 & 1.746 & 0.779 \\
\hline PMI4 & 0.5 & 400 & 10 & 1.480 & 2.480 & 1.000 \\
\hline PMI5 & 0.5 & 400 & 20 & 3.019 & 4.980 & 1.962 \\
\hline SMI1 & 0.5 & 400 & 2 & 0.145 & 0.490 & 0.345 \\
\hline SMI2 & 0.5 & 400 & 4 & 0.431 & 1.010 & 0.579 \\
\hline SMI3 & 0.5 & 400 & 7 & 0.887 & 1.740 & 0.853 \\
\hline SMI4 & 0.5 & 400 & 10 & 1.476 & 2.490 & 1.014 \\
\hline SMI5 & 0.5 & 400 & 20 & 2.995 & 4.975 & 1.980 \\
\hline
\end{tabular}

\subsection{Bonding of Chloride Ion in Concrete}

Table 4 shows the test results of chloride ion content in two mortars using different cements. It can be seen that lower free chloride ion content was confirmed in SAC mortar (SACM) as compared with the one in PC mortar (PCM) under same conditions. It indicates that SAC can bond more chloride ions from pore solution by some chemical reactions, i.e., chemical absorption. It can be explained by the fact that considerable C-HS gels provided in SACC (Wang et al., 1999) can warp chloride ions when they entered into internal concrete. The bonding ways (chemical absorption and warping action) described above support the strong bonding capacity of SACCs when they are subjected to chloride corrosion. This is very important to delay the corrosion time of reinforcements in concrete structures because these strong chloride ions can destroy alkaline protective layer of steel bars only when their content reach a critical level at the surface of reinforcements.

\subsection{Chloride Ion Diffusion in Concretes}

Chloride ion diffusion coefficient in concrete can indirectly reflect concrete ability to resist chloride ion penetration from external environment. A small chloride ion diffusion coefficient means concrete can provide good physical resistance to break/ postpone the transportation of chloride ion in internal structure of concrete. Fig. 5 shows the comparison results of chloride ion diffusion between two kinds of concretes using different water/ cement (w/c) ratios and cements. The results show cement type has a significant influence on chloride ion diffusion in concrete, especially using high $\mathrm{w} / \mathrm{c}$ ratio. This partly can be contributed to the fact that concrete can provide different pore solution/ hydration product in the internal structure of concrete when concrete has similar pore structure caused by a high w/c ratio. In theory, this can be contributed to that SAC hydration product Ettringite have as expansion property that changes pore ratio and complex degree in micro-structure of this concrete. This analysis will be investigated in the following section by experiments. Besides, the chloride ion diffusions of two kinds of concrete both increase when $\mathrm{w} / \mathrm{c}$ ratio increased, which means the chloride ion 


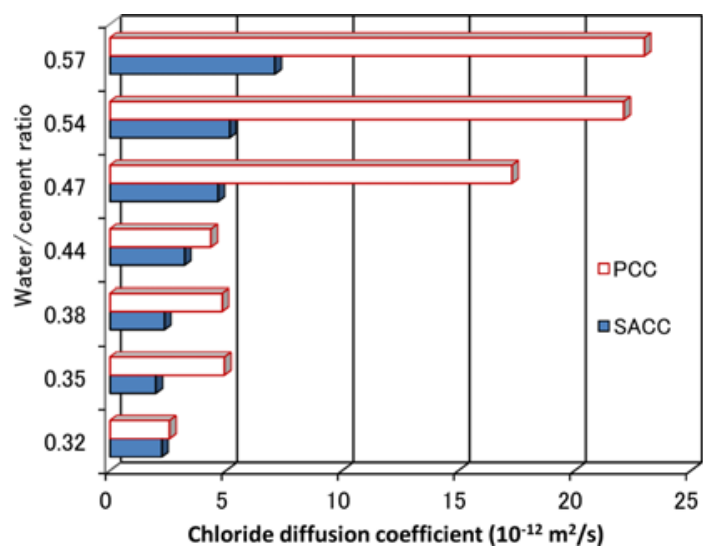

Fig. 5. Comparison of Chloride Diffusion Coefficients between SACC and PCC
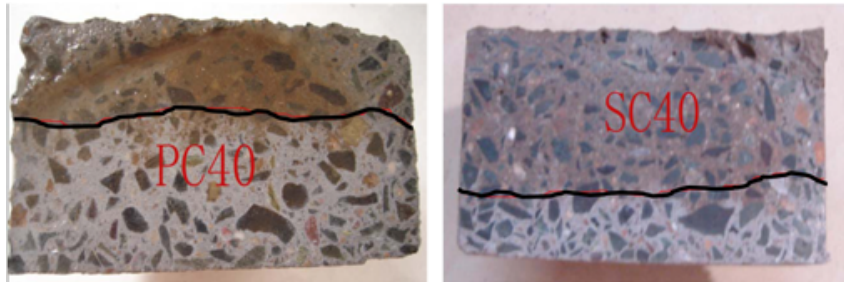

Fig. 6. Comparison between Chloride Ion Diffusion Depth in SACC and PCC

penetration resistance of the type of concrete decrease as w/c ratio. This is due to that the $\mathrm{w} / \mathrm{c}$ ratio of concrete has significant influence on the internal porosity of the two concretes affecting subsequently the transportation of chloride ion, same as reported by most researchers. In addition, the effect of w/c ratio is more intense to chloride ion diffusion into PCC, especially when the w/c ratio exceeds 0.44 . As presented in Fig. 6, comprehensively, these above observations indicate that use of SAC in concrete can increase very effectively their capacity to resist chloride ion diffusion/penetration.

\subsection{X-ray Diffraction of SACC}

To confirm the chemical change of products in SACCs after subjected to chloride ion corrosion, X-ray diffraction analyses were conducted in SACC before and after chloride ion diffuses into concrete respectively, as shown in Fig. 7. Using a standard JCPDS card, the main hydration products of this kind of concrete are Ettringite $\left(3 \mathrm{CaO} \cdot \mathrm{Al}_{2} \mathrm{O}_{3} \cdot 3 \mathrm{CaSO}_{4} \cdot 32 \mathrm{H}_{2} \mathrm{O}\right)$, Calcium silicate hydrate $(\mathrm{C}-\mathrm{S}-\mathrm{H}), \mathrm{Ca}(\mathrm{OH})_{2}$ and un-hydrated gypsum before chloride ions enter into SACC. However, when chloride ion entered into the concrete, these main products changed into Friedel's salt $\left(3 \mathrm{CaO} \cdot \mathrm{Al}_{2} \mathrm{O}_{3} \cdot \mathrm{CaCl}_{2} \cdot 10 \mathrm{H}_{2} \mathrm{O}\right)$, Ettringite, and unhydrated gypsum. It shows the capacity of bonding chloride ion of Ettringite that can provide strong reaction environment to react/absorb the chloride ion in/from internal pore solution after it (Ettringite) completely absorbed $\mathrm{OH}, \mathrm{SO}_{4}{ }^{2}$ in pore solution of the concrete, as reported by other researchers (Lan and Glasser, 1996; Wang et al., 2000, 2009). In this process, the main products

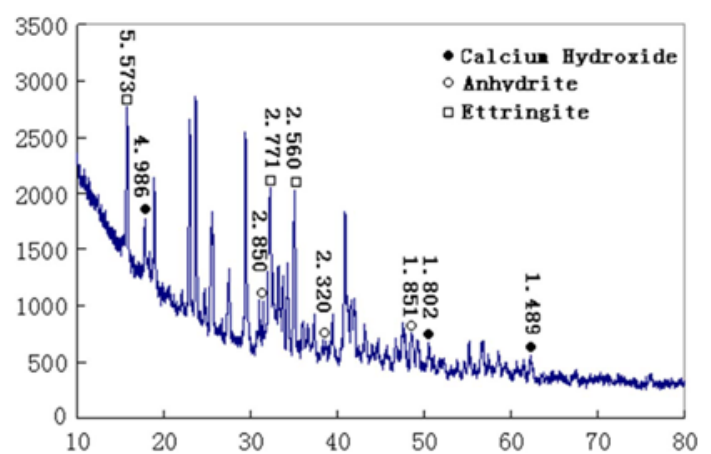

(a)

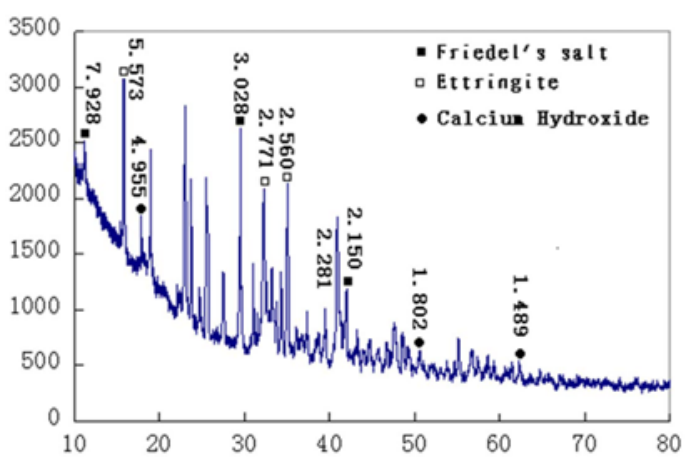

(b)

Fig. 7. XRD Patterns of SACC: (a) Before Chloride Corrosion and (b) After Chloride Corrosion

include Friedel's salt and Kuzel's salt $\left(3 \mathrm{CaO} \cdot \mathrm{Al}_{2} \mathrm{O}_{3} \cdot 0.5 \mathrm{CaSO}_{4}\right.$. $0.5 \mathrm{CaCl}_{2} \cdot 10 \mathrm{H}_{2} \mathrm{O}$ ) when Ettringite exists wet environment containing above $\mathrm{OHand} \mathrm{SO}_{4}{ }^{2}$ ions. Besides, Wang et al. $(2000,2009)$ also reported that as a special hydration product in SACC, $\mathrm{C}_{3} \mathrm{AC}_{3}$ $\left(3 \mathrm{CaO} \cdot \mathrm{Al}_{2} \mathrm{O}_{3} \cdot 3 \mathrm{CaSO}_{4} \cdot 12 \mathrm{H}_{2} \mathrm{O}\right)$ can also preferentially absorb some strong acid ions such as $\mathrm{SO}_{4}{ }^{2}$ when they exist in the pore solution with chloride ions and these strong acid ions at the same time. Subsequently, when all strong acid ions were completely consumed/absorbed, surplus $\mathrm{C}_{3} \mathrm{AC}_{3}$ will absorb chloride ion and is reacted into more stable Friedel's salt to realize the bonding and solidification of chloride ion. From this view, the content of $\mathrm{C}_{3} \mathrm{AC}_{3}$ in concrete system is a significant influence factor related to chloride ion bonding/penetration in concrete. As a result, the especial hydration reactions of the cement system make SACC to be an excellent potential construction material with the properties of chemical bonding and resisting chloride ions.

\subsection{Scanning Electron Microscopy (SEM) Analysis}

Figure 8 shows the results of SEM analyses of mortars and concretes using SAC and PC with same w/c ratio and curing condition, including the characteristics interfacial transition zone (ITZ), micro-crack, micro fillers as well as density of surficial concrete. It can be found that lots of large and long micro cracks were confirmed in PCC system, while SACC presents high level compactness and uniformity microstructure, richer filler (e.g., Ettringite) in these micro-cracks and in ITZs. These micro fillers improve the development of micro-crack and critical interface 

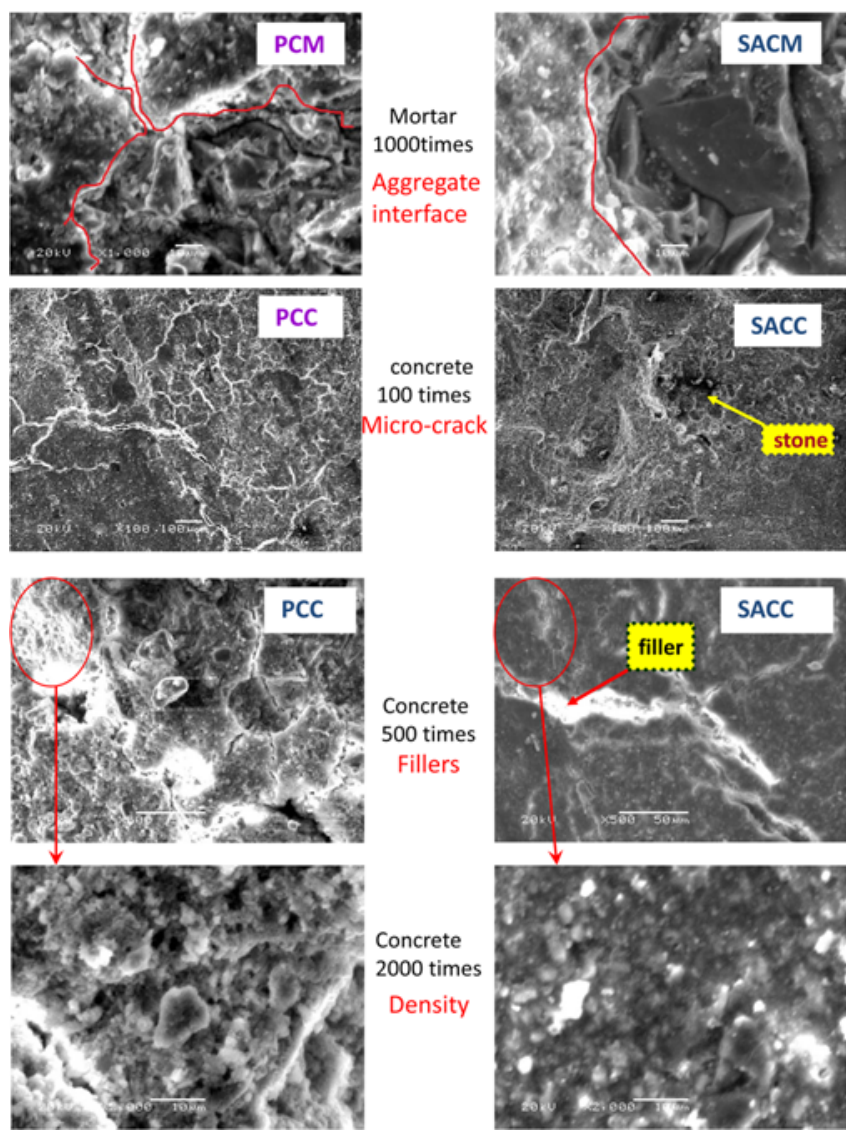

Fig. 8. SEM Analysis Results of PCM, SACM, PCC and SACC

bonding characteristic of ITZs due to its tiny expansion. The results above described support the fact that SAC can provide excellent physical internal structure to resist chloride ion diffusion in the concrete members.

\subsection{Pore Structure Analysis}

Pore structural analysis can exhibit clearly the situation of internal pore structure in concrete. This study mainly investigates the distribution of different diameter pores, porosity and tortuosity of internal pores in two above concretes. Fig. 9 shows distribution of different diameter pore in the concretes using PC and SAC. Results indicated that although the distributions of smalldiameter pore are almost same in the two kinds of concrete, the diameters of small pore in PCC principally varied from 0.01 to $0.07 \mu \mathrm{m}$, while the ones in SACC ranges from $0.01 \mu \mathrm{m}$ to 0.04 $\mu \mathrm{m}$. In addition, the influence of curing age on the change of small-pore distribution is also observed in both two types of concrete, especially when the pores have a diameter of $0.0125 \mu \mathrm{m}-0.075 \mu \mathrm{m}$. Similarly, as shown in Fig. 10, the increase of curing time has resulted in a decrease of the total porosities in SACC and PCC both, while SACC specimens always present a relative low level. Regarding large-diameter pores in these concretes, all of the tested specimens present similar distribution and their volumes can be controlled under $0.1 \mathrm{~mL} / \mathrm{g} / \mathrm{mm}$, especially when pore diameter exceeds $0.15 \mu \mathrm{m}$.

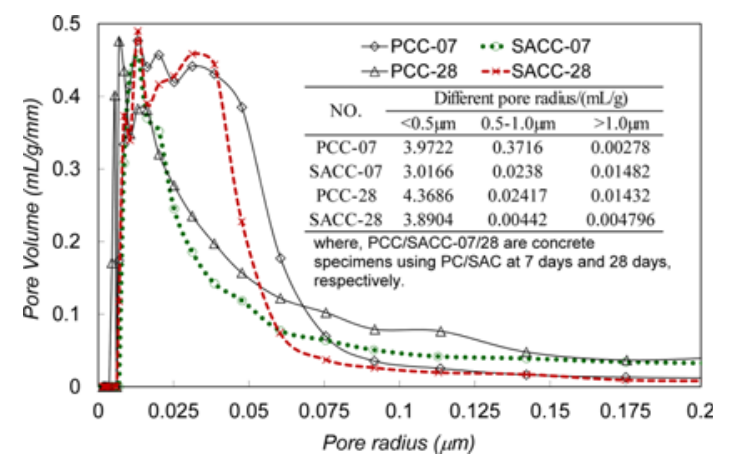

Fig. 9. Pore Structure Distribution in SACC and PCC

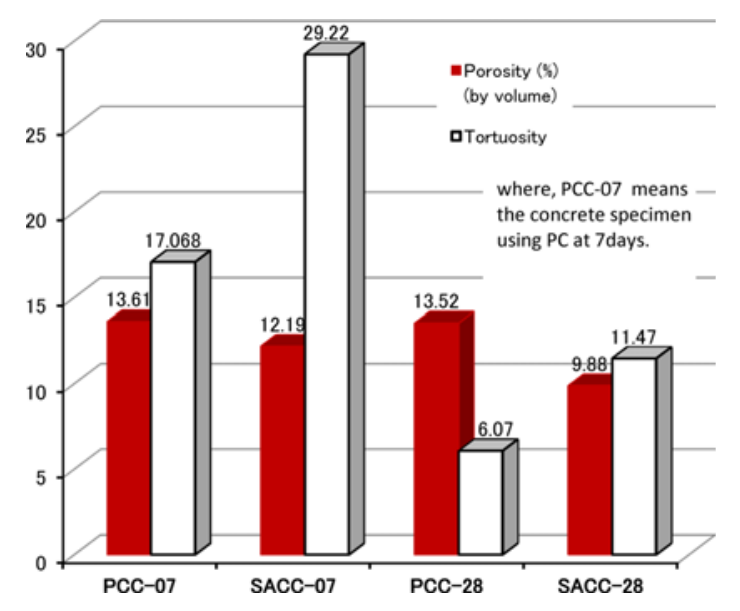

Fig. 10. Porosity and Tortuosity of Pore of SACC and PCC

In addition, the total porosity of the two concretes decrease with the increasing of curing time, however, the decrease ratios of SACC are higher than the ones of PCC. This can be contributed to that more Ettringites having micro-expansion were produced in SACC at later stages. In the aspect of pore tortuosity, on the other hand, the results plotted in Fig. 10 show the tortuosity of internal pores decreases sharply as the curing times of the two concretes increase, especially in PCCs whose decrease ratio reaches $64 \%$ while the one is $57 \%$ in SACC. The higher tortuosity level in SACC means more composited and crooked internal pore structures can be provided in this concrete. It confirmed that SACC has a better chloride ion resistance capacity because of longer transportation time of chloride ion caused by composited and crooked transportation road and less internal pore passage in concrete.

\section{Mechanism Analysis and Discussion}

On the basis of the above experimental observations and analyses, compared with conventional concrete PCC, SACC exhibited the excellent capacity to resist and bond chloride ions. This can be explained by the chemical and physical actions plotted in Fig. 11. It should be noted the two action mechanisms are not isolated, which means this cement system can provide two or more improvements for concrete to resist and bond chloride ions came 
from inside pore solution or outside environment. These mechanisms can be summarized as follows,

\subsection{Chemical Resistance}

This is a very effective chloride ion solidification way via forming some new hydrations with more stable situation/ hydration products. The chemical bonding of chloride ion of SACC can be mainly attributed to the special products of SAC such as Ettringite and rich special $\mathrm{C}_{3} \mathrm{AC}_{3}$ composition in the cement itself. The micro-expansion of Ettringite can effectively improve the microstructure and enhance absorption capacity of concrete via two ways: increase effectively compactness as filler between cracks and ITZs, as well as absorb free chloride ions in pore solution. At the same time, $\mathrm{C}_{3} \mathrm{AC}_{3}$ can absorb/react with chloride ions and transfer into more stable Friedel's salt to realize the solidification of chloride ions in this concrete.

\subsection{Physical Resistance and Warping Absorption Actions}

In this case, no new chemical reaction products appeared in microstructure of concrete. One of the physical resistance ways of SACC is mainly from strong molecule or other static attracting actions itself, which can isolate possible touching/ reactions between chloride ions and pro-chlorine compounds to resist chloride ion itself corrosion. In addition, SACC also has considerable C-H-S gel (Wang et al., 1999), which has strong absorbing capacity to warp chloride ion from the internal pore solution of concrete to solidify them. The second effective physical way is to increase transportation time or decrease the transportation road of chloride ions in concrete, by complicating the transportation way of pore water or chloride ions in concrete, such as lengthen and break the connected pores, decrease pore diameter and total porosity of concrete. As shown in Fig. 11, lower porosity of SACC can decrease significantly the transportation road for chloride ion in concrete, which can decrease the probability of the formation of coherent and slender pipeline for

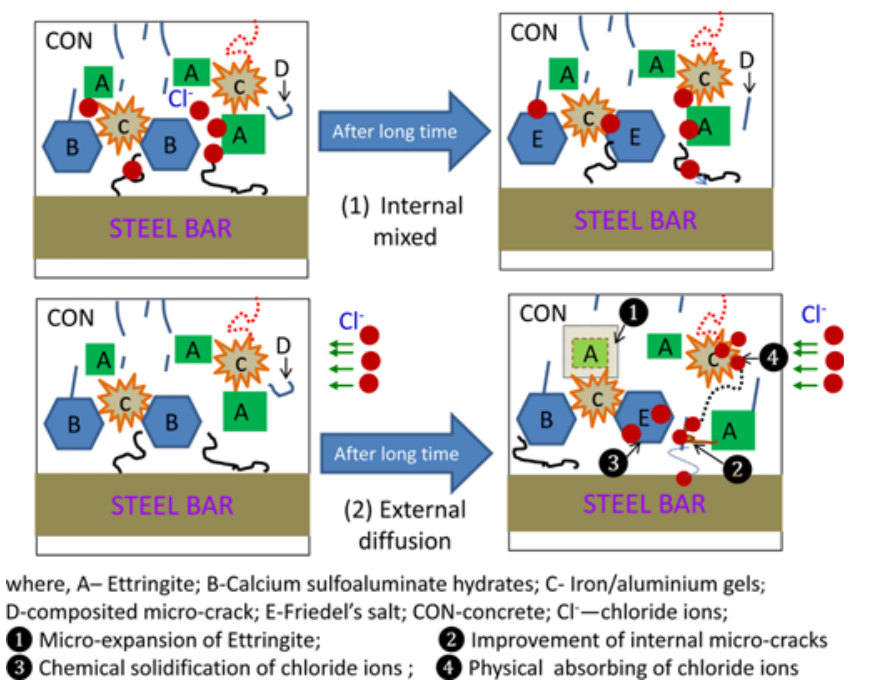

Fig. 11. Mechanism Analysis of the Bonding and Resisting of Chloride lon in SACC chloride ions. Besides, the high tortuosity pore structure of SACC indicates this concrete can provide more composited and circuitous pore distribution even when the internal pore pipelines are coherent. This is very helpful to increase the transpiration time of chloride ion in concrete from outside to the surface of reinforcement, i.e., decrease the accumulative rate of chloride ion content in concrete.

\section{Conclusions}

In this paper, a potential repair proposal for the deteriorated concrete members in chloride ion environment is proposed. To verify preliminarily this proposal, the chloride-related durability properties of SACC were investigated experimentally. The main results can be drawn as follows,

1. SACC can provide a better bonding capacity to chloride ion and hence can control effectively the chloride ion content in pore solution, which means SACC can effectively reduce the direct damage to structural members from the moveable and aggressive chloride ions.

2. Water/cement ratio and cement type are two important factors for the capacity of concrete to resist and bond chloride ions. It can be confirmed that the concrete with higher w/c ratio provide physical conditions or passageways for the ransportation of chloride ion in concrete, regardless of the type of cement. In addition, SACC can be considered as a potential solution to deal with the durability problem of existing concrete members in chloride ion rich environment, which can effectively resist the external diffusion of chloride ion by physical and chemical actions through effectively improving the internal microstructure of concrete, enhancing compactness and bonding of ITZ in concrete, as well as increasing tortuosity of internal pore structures and so on.

3. As an early strength high durability concrete repairing layer towards rescuing damaged concrete members subjected to chloride ion corrosion, SACC layer will enhance fast and effectively the resistance capacity of damaged concrete members to resist chloride ion penetration. However, up to now, just only a few studies focusing on bond characteristics between new repair layer and old concrete have been reported, which means the further studies are expected in the future to improve this proposal.

\section{References}

Abu Bakar, B. H., Putrajaya, R., and Abdulaziz, H. (2010). "Malaysian rice husk ash-improving the durability and corrosion resistance of concrete: Pre-review." Concrete Research Letters, Vol. 1, No. 1, pp. 6-13.

Alexander, M. G. and Magee, B. J. (1999). "Durability performance of concrete containing condensed silica fume." Cement and Concrete Research, Vol. 29, No. 6, pp. 917-922, DOI: 10.1016/S0008-8846 (99)00064-2.

Andac, M. and Glasser, F. P. (1999). "Pore solution composition of calcium sulfoaluminate cement." Advances in Cement Research, 
Vol. 11, No. 1, pp. 23-26, DOI: 10.1680/adcr.1999.11.1.23.

Andrade, C. (1993). "Calculation of chloride diffusion coefficients in concrete from ionic migration measurements." Cement and Concrete Research, Vol. 23, No. 3, pp. 724-742, DOI: 10.1016/0008-8846(93) 90023-3.

Angst, U., Elsener, B., Larsen, C. K., and Vennesland, Ø. (2009). Critical chloride content in reinforced concrete - a review. Cement and Concrete Research, Vol. 39, No. 12, pp. 1122-1138, DOI: 1 0.1016/ j.cemconres.2009.08.006.

Ann, K. Y., Moon, H. Y., Kim, Y. B., and Ryou, J. (2008). "Durability of recycled aggregate concrete using pozzolanic materials." Waste Management, Vol. 28, No. 6, pp. 993-9, DOI: 10.1016/j.wasman. 2007.03.003.

Bernardo, G., Telesca, A., and Valenti, G. L. (2006). "A porosimetric study of calcium sulfoaluminate cement pastes cured at early ages.' Cement and Concrete Research, Vol. 36, No. 6, pp. 1042-1047.

CE 241: Concrete Technology (2004). Various Methods of Accelerated Curing for Precast Concrete Applications, and Their Impact on Short and Long Term, Brent Vollenweider.

Chang, W., Li, H., Wei, M., Zhu, Z., Zhang, J., and Pei, M. (2009). "Effects of polycarboxylic acid based superplasticiser on properties of sulphoaluminate cement." Materials Research Innovations, Vol. 13, No. 1, pp. 7-10, DOI: 10.1179/143307509X402101.

Chindaprasirt, P., Chotithanorm, C., Cao, H. T., and Sirivivatnanon, V. (2007). "Influence of fly ash fineness on the chloride penetration of concrete." Construction and Building Materials, Vol. 21, No. 2, pp. 356-361.

Chinese test standard, SL 352-2006, Test code for hydraulic concrete, Beijing. [In Chinese]

Cordeiro, G. C., Toledo Filho, R. D., and Fairbairn, E. D. M. R. (2009). "Use of ultrafine rice husk ash with high-carbon content as pozzolan in high performance concrete." Materials and Structures, Vol. 42, No. 7, pp. 983-992, DOI: 10.1617/s11527-008-9437-z.

Crow, J. M. (2008). "The concrete conundrum." Chemistry World, Vol. 5, No. 3, pp. 62-66.

Dhir, R. K. and Jones, M. R. (1999). "Development of chloride-resisting concrete using fly ash." Fuel, Vol. 78, No. 2, pp. 137-142, DOI: 10.1016/S0016-2361(98)00149-5.

Fédération internationale du béton (1999). Structural Concrete: Textbook on Behaviour, Design and Performance: Updated Knowledge of the CEB/FIP Model Code 1990 (No. 1-3). FIB-Fed. Int. du Beton.

Geren, K. L. and Tadros, M. K. (1994). "The NU precast/prestressed concrete bridge I-girder series." PCI Journal, Vol. 39, No. 3.

Glasser, F. P. and Zhang, L. (2001). "High-performance cement matrices based on calcium sulfoaluminate-belite compositions." Cement and Concrete Research, Vol. 31, No. 12, pp. 1881-1886, DOI: 10.1016/ S0008-8846(01)00649-4.

Glasser, F. P. and Zhang, L. (2001). "High-performance cement matrices based on calcium sulfoaluminate-belite compositions." Cement and Concrete Research, Vol. 31, No. 12, pp. 1881-1886, DOI: 10.1016/ S0008-8846(01)00649-4.

Gowripalan, N. and Mohamed, H. M. (1998). "Chloride-ion induced corrosion of galvanized and ordinary steel reinforcement in highperformance concrete." Cement and Concrete Research, Vol. 28, No. 8, pp. 1119-1131, DOI: 10.1016/S0008-8846(98)00090-8.

$\mathrm{He}, \mathrm{X}$. and Shi, X. (2008). "Chloride permeability and microstructure of Portland cement mortars incorporating nanomaterials." Transportation Research Record: Journal of the Transportation Research Board, Vol. 2070, No. 1, pp. 13-21, DOI: 10.3141/2070-03.

Higginson, E. C. (1961). "Effect of steam curing on the important properties of concrete." In ACI Journal Proceedings, Vol. 58, No. 9, ACI, DOI: $10.14359 / 7984$.

Hooton, R. D. (2000). "Canadian use of ground granulated blast-furnace slag as a supplementary cementing material for enhanced performance of concrete." Canadian Journal of Civil Engineering, Vol. 27, No, 4, pp. 754-760.

Hossain, K. M. A. and Lachemi, M. (2004). "Corrosion resistance and chloride diffusivity of volcanic ash blended cement mortar." Cement and Concrete Research, Vol. 34, No. 4, pp. 695-702, DOI: 10.1016/ j.cemconres.2003.10.021.

British Standard (2007). Pore size distribution and porosity of solid materials by mercury porosimetry and gas adsorption. BS ISO 15901-1:2005.

Kasselouri, V., Tsakiridis, P., Malami, C., Georgali, B., and Alexandridou, C. (1995). A study on the hydration products of a non-expansive sulfoaluminate cement. Cement and Concrete Research, Vol. 25, No. 8, pp. 1726-1736, DOI: 10.1016/0008-8846(95)00168-9.

Kim, H. S., Lee, S. H., and Moon, H. Y. (2007). "Strength properties and durability aspects of high strength concrete using Korean metakaolin." Construction and Building Materials, Vol. 21, No. 6, pp. 1229-1237, DOI: 10.1016/j.conbuildmat.2006.05.007.

Lan, W. and Glasser, F. P. (1996). "Hydration of calcium sulphoaluminate cements at less than 24 h." Advances in Cement Research, Vol. 8, No. 31, pp. 127-134, DOI: 10.1680/adcr.2002.14.4.141.

Li, Y., Lu, L., Wand, S., Ye, Z., and Cheng, X. (2008). "Study on resistance to sulphate attack and impermeability of polymeric sulphoaluminate cement." Bulletin of the Chinese Ceramic Society, 5, 026. [In Chinese]

Lu, Y., Su, M., and Wang, Y. (1996). "Microstructural study of the interfacial zone between expansive sulphoaluminate cement pastes and limestone aggregates." Cement and Concrete Research, Vol. 26, No. 5, pp. 805-812, DOI: 10.1016/S0008-8846(96)85018-6.

Mehta, P. K. and Monteiro, P. J. (2006). Concrete: Microstructure, properties, and materials (Vol. 3). New York: McGraw-Hill.

Meng, X., Ye, Z., and Cheng, X. (2010). "Mechanical properties of sulphoaluminate cement repair mortar." Journal of University of Jinan (Science and Technology), Vol. 24, No. 1, pp. 1-4, DOI: 10.7632/J.ISSN:1671-3559.2010.01.001.

Montemor, M. F., Simoes, A. M. P., and Ferreira, M. G. S. (2003). "Chloride-induced corrosion on reinforcing steel: From the fundamentals to the monitoring techniques." Cement and Concrete Composites, Vol. 25, No. 4, pp. 491-502, DOI: 10.1016/S0958-9465(02)00089-6.

Nmai, C. K., Farrington, S. A., and Bobrowski, G. S. (1994). "Organicbased corrosion-inhibiting admixture for reinforced concrete." Concrete International, Vol. 14, No. 4, pp. 45-51.

NordTest (1999). Build 492: Concrete, mortar and cement-based repair materials: Chloride migration coefficient from non-steady-state migration experiments.

Oh, B. H., Cha, S. W., Jang, B. S., and Jang, S. Y. (2002). "Development of high-performance concrete having high resistance to chloride penetration." Nuclear Engineering and Design, Vol. 212, No. 1, pp. 221-231, DOI: 10.1016/S0029-5493(01)00484-8.

Otsuki, N., Miyazato, S. I., and Yodsudjai, W. (2003). Influence of recycled aggregate on interfacial transition zone, strength, chloride penetration and carbonation of concrete. Journal of Materials in Civil Engineering, Vol. 15, No. 5, pp. 443-451, DOI: 10.1061/ (ASCE)0899-1561(2003)15:5(443).

Qian, G. R., Shi, J., Cao, Y. L., Xu, Y. F., and Chui, P. C. (2008). "Properties of MSW fly ash-calcium sulfoaluminate cement matrix and stabilization/solidification on heavy metals." Journal of hazardous 
materials, Vol. 152, No. 1, pp. 196-203, DOI: 10.1016/j.jhazmat. 2007.06.118.

Quillin, K. (2001). "Performance of belite-sulfoaluminate cements." Cement and Concrete Research, Vol. 31, No. 9, pp. 1341-1349, DOI: 10.1016/S0008-8846(01)00543-9.

Rongbing, B. and Jian, S. (2005). "Synthesis and evaluation of shrinkagereducing admixture for cementitious materials." Cement and Concrete Research, Vol. 35, No. 3, pp. 445-448, DOI: 10.1016/j.cemconres. 2004.07.009.

Ryu, J. S. (2002). "Improvement on strength and impermeability of recycled concrete made from crushed concrete coarse aggregate." Journal of Materials Science Letters, Vol. 21, No. 20, pp. 15651567, DOI: 10.1023/A:1020349011716.

Shi, X., Xie, N., Fortune, K., and Gong, J. (2012). "Durability of steel reinforced concrete in chloride environments: An overview." Construction and Building Materials, Vol. 30, pp. 125-138, DOI: 10.1016/j.conbuildmat.2011.12.038.

Shideler, J. J. and Chamberlin, W. H. (1949). "Early strength of concrete as affected by steam curing temperatures." In ACI Journal Proceedings, Vol. 46, No. 12, ACI, DOI: 10.14359/12057.

Vázquez, E., Barra, M., Aponte, D., Jiménez, C., and Valls, S. (2014). Improvement of the durability of concrete with recycled aggregates in chloride exposed environment.

Vazquez, E., Barra, M., Aponte, D., Jimenez, C., and Valls, S. (2014). "Improvement of the durability of concrete with recycled aggregates in chloride exposed environment." Construction and Building Materials, Vol. 67, No. part A, pp. 61-67, DOI: 10.1016/j.conbuildmat.2013. 11.028 .

Wang, F., Zhu, Y., and Zhang, L. (2009). "Experimental research of sodium chloride on activity excited ability and binding mode of fly ash portland blend cement." Bulletin of the Chinese Ceramic Society, 1, Vol. 28, No. 1, pp. 31-37. [In Chinese]

Wang, S., Huang, Y., and Wang Z. (2000). "Concrete resistance to chloride ingress: Effect of composition." Journal of the Chinese Ceramic Society, Vol. 28, No. 6, pp. 570-574. [In Chinese]

Wang, Y., Su, M., and Zhang, L. (1999). Sulphoaluminate cement, Beijing University of Technology Press, Beijing. [In Chinese]

Xin, C., Jun, C., Lu, L., Liu, F., and Teng, B. (2000). "Study of Babearing calcium sulphoaluminate minerals and cement." Cement and Concrete Research, Vol. 30, No. 1, pp. 77-81, DOI: 10.1016/ S0008-8846(99) 00204-5.

Xin, C., Shifeng, H., Jun, C., Ronghua, X., Futian, L., and Lingchao, L.
(2005). "Piezoelectric and dielectric properties of piezoelectric ceramicsulphoaluminate cement composites." Journal of the European Ceramic Society, Vol. 25, No. 13, pp. 3223-3228.

Yan, P. (1993). "Hydration of Sr-and Ba-bearing sulphoaluminates in the presence of sulphates." Advances in Cement Research, Vol. 5, No. 18, pp. 65-69, DOI: 10.1680/adcr.1993.5.18.65.

Ye, Z., Chang, J., Lu, L., and Cheng, X. (2007). "Study of impermeability of ba-containing sulphoaluminate cement concrete." Journal of Building Materials, 588-91. [In Chinese]

Yeau, K. Y. and Kim, E. K. (2005). "An experimental study on corrosion resistance of concrete with ground granulate blast-furnace slag." Cement and Concrete Research, Vol. 35, No. 7, pp. 1391-1399, DOI: 10.1016/j.cemconres.2004.11.010.

Zhang, M. H. and Li, H. (2011). "Pore structure and chloride permeability of concrete containing nano-particles for pavement." Construction and Building Materials, Vol. 25, No. 2, pp. 608-616, DOI: 10.1016/ j.conbuildmat.2010.07.032.

Zhang, P. and Wang, Z. (1993). "Application of Sulphoaluminate cement in negative temperature concrete." Low temperature of architectural technology, 3:003.[In Chinese]

Zhao, J., Cai, G. C., and Gao, D. Y. (2011a). "Study on bonding characteristic of mixed-type chloride ion in sulphoaluminate cement." Key Engineering Materials, Vol. 467, pp. 698-702, DOI: 10.4028/ www.scientific.net/KEM.467-469.698.

Zhao, J., Cai, G, and Gao, D. (2011b). "Analysis of mechanism of resistance to chloride ion erosion of sulphoaluminate cement concrete." Journal of Building Materials, Vol. 14, No. 3, pp. 357-361, DOI: 10.3969/j.issn.1007-9629.2011.03.013.

Zhao, J., Cai, G., Gao, D., and Zhao, S. (2014). "Influences of freezethaw cycle and curing time on chloride ion penetration resistance of Sulphoaluminate cement concrete." Construction and Building Materials, Vol. 53, pp. 305-311, DOI: 10.1016/j.conbuildmat.2013. 11.110 .

Zhou, Q., Milestone, N. B., and Hayes, M. (2006). "An alternative to Portland cement for waste encapsulation - the calcium Sulfoaluminate cement system." Journal of Hazardous Materials, Vol. 136, No. 1, pp. 120-129, DOI: 10.1016/j.jhazmat.2005.11.038.

Zornoza, E., Garcés, P., Payá, J., and Climent, M. A. (2009). "Improvement of the chloride ingress resistance of OPC mortars by using spent cracking catalyst." Cement and Concrete Research, Vol. 39, No. 2, pp. 126-139, DOI: 10.1016/j.cemconres.2008.11.006. 